\title{
A versatile, solvent-free methodology for the functionalisation of carbon nanotubes
}

\author{
Robert Menzel, ${ }^{a}$ Michael Q. Tran, ${ }^{b}$ Angelika Menner, ${ }^{b}$ Chris Kay, ${ }^{c}$ Alexander Bismarck, ${ }^{b}$ and Milo SP \\ Shaffer ${ }^{*} a$
}

\author{
${ }_{5}$ Received (in $\left.X X X, X X X\right)$ Xth $X X X X X X X X X 200 X$, Accepted Xth XXXXXXXXX 200X \\ First published on the web Xth $X X X X X X X X X 200 X$ \\ DOI: $10.1039 / b 000000 x$
}

High temperature activation of carbon nanotubes (CNTs) provides a new and highly versatile functionalisation strategy. The reaction allows the attachment of a wide variety of functional 10 species onto the nanotube surface at grafting ratios between $1-8 \mathrm{wt} \%$, whilst maintaining the intrinsic properties of the untreated materials. The underlying reaction mechanism has been established by quenching experiments and EPR studies. The distribution of the functionalised sites has been investigated at the microscopic scale using tagging reactions. The grafted products have been characterized by electron microscopy, thermal analysis (TGA), Raman spectroscopy, and

15 inverse gas chromatography (IGC). The change in the CNT surface properties after grafting has been quantified in terms of dispersive and specific surface energies, and altered dispersibilities in a broad range of solvents. It is possible to carry out the reaction using gas phase reagents, providing a clean, efficient, and scalable methodology, relevant to a diverse range of applications.

\section{Introduction}

20 It has long been known that heating of graphitic materials under inert atmospheres to around $1000^{\circ} \mathrm{C}$ leads to the decomposition of the surface oxides. ${ }^{1}$ Depending on the temperature at which the material is re-exposed to air, the surface oxides subsequently reform as either acidic or basic 25 surface groups. 2,3 The mechanism has not been elucidated, but these literature findings hint at the formation of active radicals on the graphitic surface, during high temperature treatment, which later trap oxygen. On that basis, we have investigated the hypothesis that the thermally-activated 30 carbons ought to bind covalently, not just oxygen, but a wide variety of functional molecules, including polymerisable monomers. In particular, we have demonstrated the effect using carbon nanotubes (CNTs), for which new, more practical, functionalisation strategies are urgently sought.

${ }_{35}$ Due to their exceptional structural, electrical, and mechanical properties, ${ }^{4,5}$ CNTs are relevant to a wide range of applications, including engineering, ${ }^{6}$ bionanotechnology, ${ }^{7}$ and catalysis. ${ }^{8,9}$ Chemical modification is frequently required, in order to compatibilise the nanotubes with a particular 40 environment or to attach functional components. ${ }^{10-12}$ For these reasons, strategies for the covalent functionalisation of CNTs have been intensively explored in recent years; ${ }^{12}$ numerous wet-chemical reactions are available, allowing the introduction of a wide range of functional surface groups. ${ }^{11,13}$

${ }_{45}$ Examples include the chemical derivatisation of oxygencontaining functional groups at defect sites, e.g. through classical amidation or esterfication reactions, ${ }^{14}$ and direct functionalisation of the graphitic CNT sidewalls, such as reactions with nitrenes, ${ }^{15}$ carbenes $^{16}$ and diazonium salts. ${ }^{17}$

${ }_{50}$ Since covalent modification of the CNT structure damages the intrinsic properties of interest, it is often desirable to attach macromolecular species that multiply the number of functional groups attached per reactive site on the nanotube surface. ${ }^{18}$ Free radical reactions are a common approach to 55 nanotube functionalisation and macromolecule grafting, specifically; they divide into two general strategies. ${ }^{19}$ In the "grafting-to" approach, free radicals are generated in the supporting solvent and subsequently terminated on the CNT surface; examples include the reaction of CNTs with pre60 synthesised, azide- or nitroxyl-terminated macromolecules ${ }^{20}$, ${ }^{21}$, or photolysable organic iodides. ${ }^{22}$ The "grafting-from" approach involves the polymerisation of monomers from traditional initiating species that have been first immobilised on the nanotube surface. ${ }^{11}$ Living radical polymerization 65 methods, including atom transfer radical polymerization, ${ }^{23}$ nitroxide-mediated polymerization, ${ }^{24}$ and reversible additionfragmentation chain transfer polymerization, ${ }^{25}$ have been frequently employed for this purpose due to their tolerance to a wide variety of functional groups.

70 These conventional, wet-chemical, CNT derivatisation reactions are typically time-consuming and inconvenient, frequently requiring multiple reaction steps and/or lengthy filtration/centrifugation procedures for purification. In addition, they typically create large volumes of liquid waste, 75 consisting of toxic organic solvent or corrosive mineral acids which can significantly limit the economical viability of these approaches. There is, therefore, a need to develop simpler, solvent-free methodologies. Although several, dry functionalisation methods have been reported, including direct 80 fluorination, ${ }^{26}$ thermal oxidation, ${ }^{27}$ and plasma treatments, ${ }^{28}$ unfortunately, these reactions often lead to significant degradation of the graphitic framework and intrinsic CNT properties, and suffer from poor reproducibility and versatility. In this paper, we present an alternative, 85 thermochemical functionalisation approach extending an existing method developed to alter the surface oxide chemistry of carbon materials, including carbon fibres ${ }^{29}$ and 
CNTs. $^{27}$

\section{Experimental}

CNTs were synthesised in our laboratory (in-house CNTs) employing standard CVD-growth conditions yielding mats of 5 relatively straight and aligned, large multi-wall carbon nanotubes (outer diameter 80-100 nm, length of a few hundreds micrometres). ${ }^{30}$ Commercial, CVD-grown CNTs were obtained from Arkema SA (Lacq-Mourenx, France) and Nanocyl SA (Sambreville, Belgium) and consisted of 10 aggregates of entangled CNTs with outer diameters of around 10-20 nm and lengths at least a few micrometres. Prior to the thermochemical treatment, the as-received or as-synthesized CNTs were pre-oxidised by heating in air $\left(670{ }^{\circ} \mathrm{C}\right.$, cycles of 6 $\mathrm{x} 5 \mathrm{~min}$ ) in order break-up the entangled CNT agglomerates 15 and introduce additional oxygen-containing functional groups onto the CNT surface. ${ }^{27}$ These pre-oxidised CNTs are referred to as "parent" CNTs in this paper.

The grafting was carried out in a custom-made setup consisting of a $30 \mathrm{~mm}$ diameter quartz tube attached to a 20 sample flask (Figure 1). In order to work under air-free conditions, the setup was connected to an inert gas source or a vacuum system.

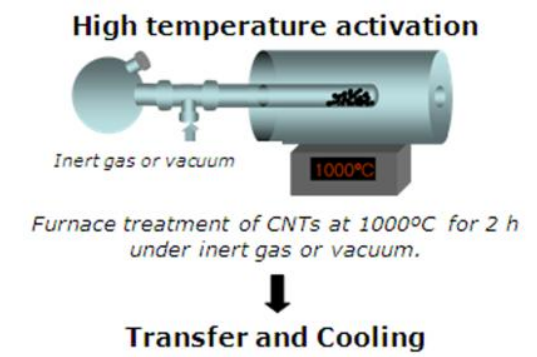

Transfer of activated CNTs to reaction flask by gravity and cool down to room temperature under inert gas or vacuum.

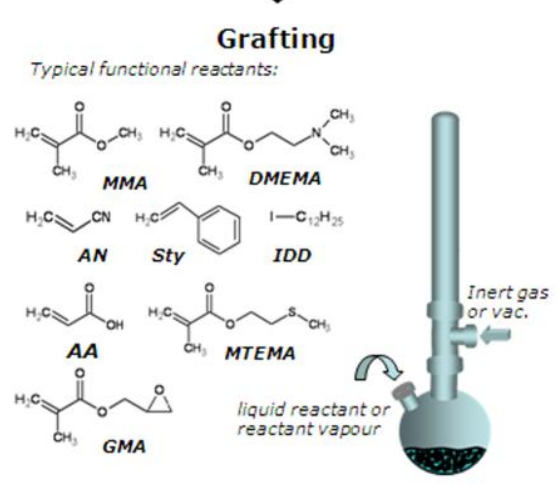

Exposure of activated CNTS to a functional organic reactant in its liquid or vapour form under inert gas or vacuum.

Figure 1. Schematic overview of the thermochemical grafting of carbon 25 nanotubes with functional organic reactnats. Refer to the ESI (Table 1) for further details about the organic reactants used.

$100 \mathrm{mg}$ CNTs were heated to $1000{ }^{\circ} \mathrm{C}$ under oxygen-free nitrogen or vacuum $\left(5 \cdot 10^{-4} \mathrm{mbar}\right)$ at $15 \mathrm{~K} / \mathrm{min}$ in a conventional three-zone tube furnace (PTF 12/38/500, Lenton
${ }_{30} \mathrm{Ltd}, \mathrm{UK}$ ) and held at that temperature for $2 \mathrm{~h}$. In a second step, the quartz tube was slowly removed from the heating zone and allowed to cool to room temperature. The CNTs were transferred to the round bottom flask by gravity. $3 \mathrm{~mL}$ of the reactant (Figure 1) were injected either directly into the

35 flask containing the thermally-activated sample (liquid-phase setup) or into an empty reservoir attached to the sample flask (gas-phase setup). After leaving the sample-monomer mixture under inert atmosphere or vacuum for $12 \mathrm{~h}$, non-reacted reactant was removed via filtration. Prior to characterisation, 40 the product was thoroughly washed three times in order to remove any physiosorbed reactants. Each washing step consisted of bath sonication for $5 \mathrm{~min}$ in $50 \mathrm{~mL}$ of the washing agent, filtration and rinsing with $3 \times 50 \mathrm{~mL}$. For comparative reasons, these washing steps were also applied to 45 the products synthesized using the gas-phase setup. The washing procedure was a requirement for the detailed fundamental study in this paper; for application, simple removal and recovery of excess reactant via evaporation under vacuum, without using any solvents, should be sufficient.

${ }_{50}$ Futher experimental details can be found in the ESI.

\section{Results and discussion}

As an illustration, commercial CNTs were high-temperature activated and treated with lauryl methacrylate (LMA) in oxygen-free nitrogen using the liquid-phase experimental 55 setup followed by washing with toluene. Thermogravimetric analysis (TGA) of the LMA-treated sample in air confirmed successful grafting (Figure 2(a)).
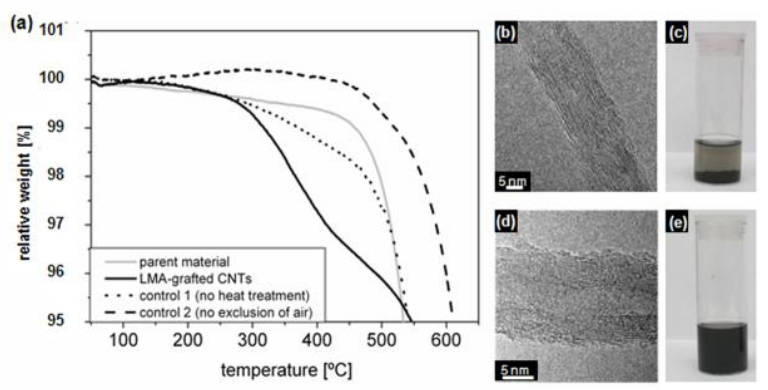

Figure 2. Characterization of CNTs grafted with lauryl methacrylate (LMA): TGA weight loss profiles of LMA-grafted CNTs and corresponding control samples (a); HRTEM images of parent CNT (b) and LMA-grafted CNT (d); dispersion of parent CNTs (c) and LMAgrafted CNTs (e) in butyl acetate.

Prior to the combustion of the CNTs at around $600^{\circ} \mathrm{C}$ (only 65 the onsets are shown in Figure 2(a), see ESI for full TGA curves), a small but distinct weight loss was observed at around $355^{\circ} \mathrm{C}$ (Figure 2(a)), associated with a clear peak in the derivative curve and indicating the combustion of the grafted organics. Two control experiments were carried out 70 under identical treatment conditions. For control experiment 1, the parent CNTs were mixed with the LMA monomer under inert gas, omitting the high-temperature treatment; for control experiment 2, the heat-treated CNTs were mixed with LMA only after exposure to air for $1 \mathrm{~h}$. The products underwent the 75 same washing procedure as applied for the LMA-grafted 
CNTs. The first control showed a very small, broad weightloss, with no peak in the derivative; the feature can be attributed to modest physisorption on the heterogeneous CNT surface ${ }^{31}$ caused either by the adsorption of LMA monomer 5 in slit pores or on iron impurities inherently present in these CNTs. In the second control, the slightly rising profile and increased thermal stability of the CNTs is consistent with the presence of stable basic surface oxides; it has been shown previously that heat-activated carbons exposed to air at room 10 temperature form stable basic and ether-type oxygencontaining surface groups ${ }^{3,}, 32$ that decompose at elevated temperatures following take up of additional oxygen, ${ }^{27,} 33$ explaining the initial weight gain observed. The consistently different weight loss profiles (Figure 2(a)), therefore, confirm 15 that high-temperature activation and the exclusion of air are prerequisites for successful LMA grafting. From the TGA weight loss profile (Figure 2(a)), the LMA grafting ratio (i.e. the weight of the chemisorbed organic monomer relative to the total weight of the product) can be estimated to be 3.0 $20 \mathrm{wt} \%$ (see also Figure 1 in the ESI) which roughly equates to a CNT surface coverage of around $20 \%$. After three repeats, the reproducibility of LMA-grafting reaction was estimated to be $\Delta=(2.8 \pm 0.8) \mathrm{wt} \%$. Due to the rough surface and beam sensitivity of organic molecules, it is not surprising that the 25 grafted monomer cannot be resolved in HRTEM images (Figure 2 (d)). However, a clear change in CNT surface character after grafting was detected via inverse gas chromatography, a sensitive analytical technique which allows the determination of dispersive surface energies, $\gamma^{\mathrm{d}}$ (reflecting

${ }_{30}$ CNT surface properties purely due to London forces) and specific surface characteristics (measured in terms of acceptor and donor numbers, $\mathrm{K}_{\mathrm{A}}$ and $\mathrm{K}_{\mathrm{D}}$, quantifying the ability of the CNT surface to undergo electron accepting and donating interactions). ${ }^{31}$ After LMA-grafting, the dispersive surface 35 energy, $\gamma^{\mathrm{d}}$, of the CNTs is significantly reduced from $(113 \pm 2)$ $\mathrm{mJ} / \mathrm{m}^{2}$ to $(87 \pm 2) \mathrm{mJ} / \mathrm{m}^{2}$, which is consistent with the occupation or replacement of high-energy sites on the CNT surface with organic monomers. ${ }^{34}$ In addition, the $\mathrm{K}_{\mathrm{D}} / \mathrm{K}_{\mathrm{A}}$ ratio increased from $2.3 \pm 0.1$ to $3.1 \pm 0.1$, indicating a more 40 pronounced electron-donating surface character due the introduction of methacrylic units onto the CNT surface. These changes in dispersive and specific surface character are sufficient to alter the dispersion behavior, markedly. Compared to the parent material, the dispersibility of the ${ }_{45}$ LMA-grafted CNTs in butyl acetate increased by a factor of ten, from 3 to $35 \mathrm{mg} / \mathrm{L}$ (Figure 2(c) and (e)), but substantially decreased by a factor of five in ethanol (Table 2). These differences in dispersibility were even more pronounced when the LMA-grafted product was compared to the 'air50 exposed'control sample (Table 1) which has a relatively less polar surface than the parent material.

The two control experiments in Figure 2(a) show that reactive sites are generated during the heat activation step (unlike control experiment 1) but are quenched when exposed 55 to air (control experiment 2). The nature of these reactive sites was further studied using EPR spectroscopy, which allows the detection of species with unpaired electrons. The EPR spectrum of the heat-treated commercial CNTs in vacuum exhibited a relatively narrow signal (g-factor of around 2.01) 60 at a measurement temperature of $6 \mathrm{~K}$, a temperature regime where the EPR spectrum of conducting materials, such as CNTs, are expected to be dominated by localized spins, such as radicals and paramagnetic ions, rather than by the spin resonance of their delocalized conduction electrons. ${ }^{35-38}$ The ${ }_{65}$ EPR signal observed was quenched when the CNTs were exposed to air. These observations support the hypothesis that reactive radicals form on the $\mathrm{CNT}$ surface, associated with the desorption of surface oxides at high temperatures.
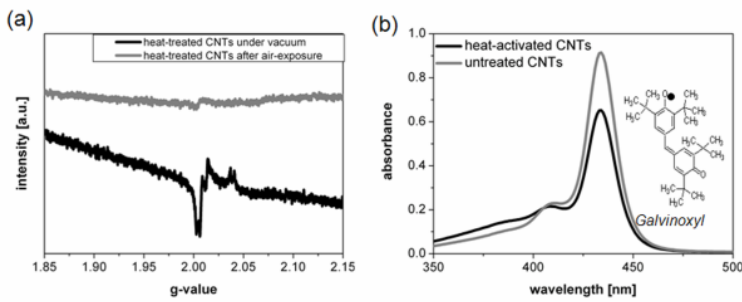

70 Figure 3. (a) EPR spectra of heat-treated Arkema CNTs in vacuum and after air exposure for $1 \mathrm{~h}$, recorded at $6 \mathrm{~K}$ (the corresponding EPR spectra at room temperature are available in the Supplementary Information); (b)

$\mathrm{UV}$-Vis spectra of a pure galvinoxyl (GO) solution in toluene after mixing with heat-activated commercial CNTs and untreated Arkema 75 CNTs under vacuum, respectively.

Further quenching studies were carried out to estimate the radical concentration, using galvinoxyl, an air-stable radical with a characteristic UV-Vis absorption band at $434 \mathrm{~nm}$. The absorption intensity of galvinoxyl in toluene only marginally 80 changed when mixed with as-received CNTs but significantly decreased when added to the heat-activated CNTs (Figure 3 (b)) presumably due to the binding of galvinoxyl radicals from solution to the radicals on the CNT surface. By assuming that one galvinoxyl radical is quenched by one surface radical, 85 the concentration of the active sites on the CNT can be calculated to $31 \mu \mathrm{mol}$ per gram of CNTs. In a second, independent, quenching experiment, thermally-activated CNTs were reacted with iodododecane resulting in the grafting ratio of $0.9 \mathrm{wt} \%$ (Figure 5). Again assuming a 90 stochiometric reaction, this grafting ratio corresponds to a radical concentration of $50 \mu \mathrm{mol} / \mathrm{g}$. The two independent quenching experiments indicate similar surface radical concentrations; for the remainder of this paper, we will use an average value of $40 \mu \mathrm{mol} / \mathrm{g}$ as an estimate for the 95 concentration of grafting sites on the CNT surface. The grafting site concentration is significantly lower than the surface concentration of oxygen-containing groups on the parent CNTs which was determined to be about $150 \mu \mathrm{mol} / \mathrm{g}$ by Böhm's titration with $\mathrm{NaOH}$. This difference suggests that 100 only certain types of surface oxides are precursors for the radicals, whilst the majority desorb in a heterolytic fashion or undergo migration and restructuring processes during the high temperature treatment. ${ }^{39,40}$ At a grafting ratio of $2.8 \mathrm{wt} \%$ LMA, i.e. $110 \mu$ mol LMA per gram CNT, there are about 105 three times more monomeric units than grafting sites present on the CNT surface, implying that radical polymerization of the methacrylate has been initiated by the radicals at the Arkema CNT surface (i.e. a "grafting from" mechanism). ${ }^{11}$ 
Termination of the polymerization process may occur either through trace impurities in the reaction system, or via recombination of the propagating chain with a second radical site, resulting in oligomer loops on the CNT surface (Figure 54). The latter option is likely to be favoured kinetically, leading to the low grafted molecular weight. On this basis, the covalently-bound LMA oligomers can be estimated to consist of six monomer repeats.
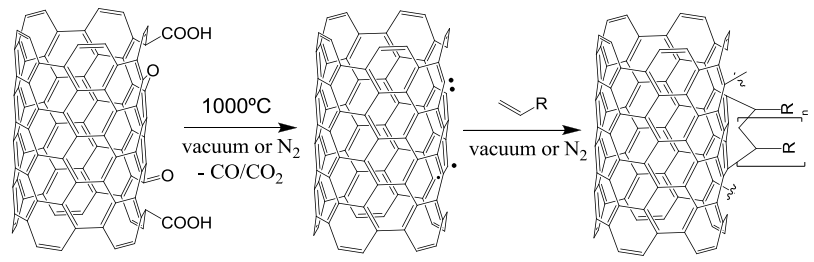

Figure 4. Proposed mechanism for the thermochemical activation and grafting of CNTs.

The proposed grafting mechanism implies that the generation of the reactive sites on the CNT surface does not cause any significant additional damage to the graphitic 15 network beyond the original oxidation; this assumption is confirmed by Raman measurements, which yield similar $\mathrm{I}_{\mathrm{G}} / \mathrm{I}_{\mathrm{D}}$ ratios for the parent $(0.85 \pm 0.7)$ and LMA-grafted $(0.81 \pm 0.6)$ materials.

The underlying radical mechanism of the grafting reaction 20 suggests that the thermochemical treatment approach should be a versatile methodology for the surface modification of CNTs. The generality was, therefore, tested using CNTs of different dimensions and morphologies, and various reactants capable of reacting with radicals, including methacrylates, 25 styrenes, and organic iodides (Figure 5 and Table 1).
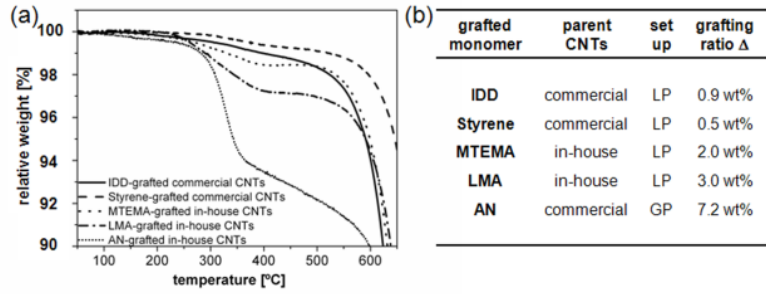

Figure 5. Versatility of the thermochemical grafting approach: (a) TGA weight loss profiles, and (b) grafting ratios for commercial and in-house grown CNTs grafted with various organic compounds. For acronyms and 30 structures of the grafted compounds see Table 1.

One particularly important question, often ignored in CNT chemistry, is how the reactive sites are distributed within the sample; this issue was probed using a tagging reaction. Similar approaches have been used previously for 35 conventional wet-chemistry. ${ }^{41}$ In-house produced CNTs were grafted with both LMA and 2-(methylthio) ethyl methacrylate (MTEMA). By tagging the sulphur groups in MTEMA with gold colloids, the markedly different surface character of the two modified samples was confirmed (Figure 6). While 40 scanning electron micrscopy images show binding of the gold particles to the MTEMA-grafted CNTs, no tagging of the LMA-grafted control sample is observed. Although a one-toone correlation is unlikely for steric and other reasons, the location of the gold colloids in Figure 6 visualizes the 45 distribution of the grafting sites on the CNT surface. Grafting occurs along the whole length of the nanotubes and is probably associated with the presence of graphene edges and defects sites in the CNT sidewalls. Transmission electron microscopy studies (not shown) failed to show a conclusive 50 relationship between the gold nanoparticles location and defect structures probably due to the difficulty of imaging all types of defects in the relevant orientation. Figure 6(a) also implies that functionalisation occurs in a relatively homogeneous fashion. On the macroscale, this observation is 55 supported by the relatively good repeatability of the TGA experiments, with the resulting grafting ratios typically exhibting an error of around $10 \%$. However, questions of homogeneity might need to be resolved on scale-up of the reaction due to issues with heat transfer and penetration of 60 organic reactant.
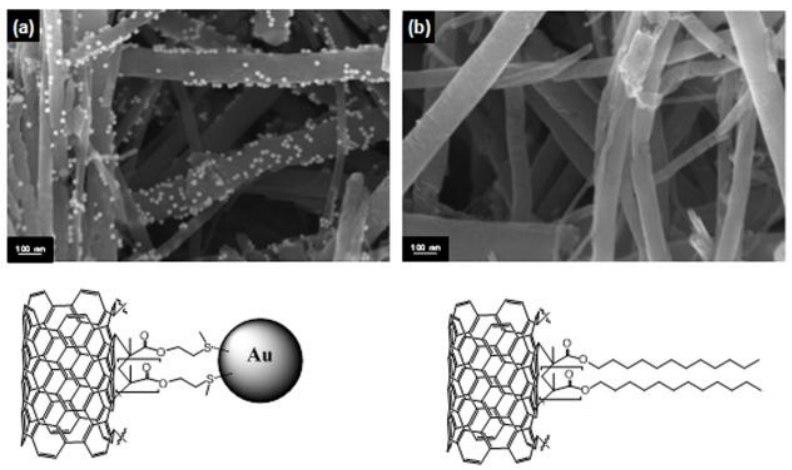

Figure 6. SEM images of in-house CNTs grafted with (a) MTEMA and (b) LMA after exposure to a dispersion of gold nanoparticles, followed by thorough washing in both cases.

65 Various other functional vinyl compounds were grafted onto commercial CNTs. The grafting ratios and average oligomer chain lengths varied significantly with the monomer used and reached values up to $8 \mathrm{wt} \%$ and around 70 monomeric units, respectively, for the most reactive 70 compounds (Table 1 ). 
Table 1: Overview of commercial CNTs grafted with various functional organic compounds and some of their properties, including average chain length of the grafted oligomers (assuming formation of oligomer loops). For acronyms and structures of grafted compounds see Table 1.

\begin{tabular}{|c|c|c|c|}
\hline $\begin{array}{l}\text { grafted } \\
\text { compound }\end{array}$ & Setup & $\begin{array}{c}\text { grafting } \\
\text { ratio } \Delta \\
{[w t \%]}\end{array}$ & $\begin{array}{c}\text { Mono- } \\
\text { meric } \\
\text { units }\end{array}$ \\
\hline Parent CNTs & $\mathrm{n} / \mathrm{a}$ & $\mathrm{n} / \mathrm{a}$ & $\mathrm{n} / \mathrm{a}$ \\
\hline $\begin{array}{l}\text { Air-exposed } \\
\text { CNTs }\end{array}$ & $\mathrm{n} / \mathrm{a}$ & $\mathrm{n} / \mathrm{a}$ & $\mathrm{n} / \mathrm{a}$ \\
\hline Sty & LP & 0.5 & 2 \\
\hline IDD & LP & 0.9 & 1 \\
\hline MMA & GP & 2.3 & 10 \\
\hline MMA & LP & 2.5 & 12 \\
\hline LMA & LP & 2.8 & 6 \\
\hline GMA & LP & 3.0 & 6 \\
\hline DMAEMA & LP & 5.2 & 16 \\
\hline AN & GP & 7.2 & 68 \\
\hline AN & LP & 7.3 & 68 \\
\hline AA & LP & 7.9 & 54 \\
\hline
\end{tabular}

Table 2: Overview of commercial CNTs grafted with various functional organic compounds and some of their properties, including dispersive surface energy (standard deviations $\sigma<2 \mathrm{~mJ} / \mathrm{m}^{2}$ ), ratio of electron donor and acceptor numbers $\mathrm{K}_{\mathrm{D}} / \mathrm{K}_{\mathrm{A}}(\sigma<0.2)$, and dispersibility data $(\sigma<2$ $10 \mathrm{mg} / \mathrm{L}$ ). For acronyms and structures of grafted compounds see Table 1.

\begin{tabular}{|c|c|c|c|c|c|c|}
\hline \multirow{2}{*}{$\begin{array}{l}\text { grafted } \\
\text { compound }\end{array}$} & \multirow{2}{*}{$\begin{array}{l}\text { set- } \\
\text { up }\end{array}$} & \multirow{2}{*}{$\begin{array}{c}\text { disp. } \\
\text { surface } \\
\text { energy } \gamma^{d} \\
{\left[\mathrm{~mJ} / \mathrm{m}^{2}\right]}\end{array}$} & \multirow{2}{*}{$\mathrm{K}_{\mathrm{D}} / \mathrm{K}_{\mathrm{A}}$} & \multicolumn{3}{|c|}{$\begin{array}{c}\text { concentration of dispersed } \\
\text { CNTs }[\mathrm{mg} / \mathrm{L}]\end{array}$} \\
\hline & & & & $\begin{array}{l}\text { butyl } \\
\text { acetate }\end{array}$ & $\begin{array}{l}\text { etha- } \\
\text { nol }\end{array}$ & $\begin{array}{l}\text { water } \\
(\mathrm{pH} 4)\end{array}$ \\
\hline $\begin{array}{l}\text { Parent } \\
\text { CNTs }\end{array}$ & $\mathrm{n} / \mathrm{a}$ & 113 & 2.3 & 3.2 & 14.0 & 0.1 \\
\hline $\begin{array}{l}\text { Air- } \\
\text { exposed } \\
\text { CNTs }\end{array}$ & $\mathrm{n} / \mathrm{a}$ & 110 & 2.4 & 0.3 & 2.3 & 0.1 \\
\hline Sty & LP & 108 & 2.5 & & & \\
\hline IDD & LP & 101 & 2.7 & & & \\
\hline MMA & GP & 83 & 3.0 & & & \\
\hline MMA & LP & 81 & 3.2 & 30.7 & 1.6 & 0.2 \\
\hline LMA & LP & 87 & 3.1 & 35.6 & 2.6 & 0.2 \\
\hline GMA & LP & 84 & 2.6 & & & \\
\hline DMAEMA & LP & 85 & 2.9 & 2.1 & 5.3 & 8.7 \\
\hline AN & GP & 81 & 2.6 & 42 & 21 & 0.1 \\
\hline AN & LP & 77 & 2.5 & & & \\
\hline AA & LP & 60 & 1.9 & & & \\
\hline
\end{tabular}

Compared to both the untreated parent material and the 'air-exposed' control sample, the solvent dispersibility of the modified CNTs improved significantly, in a range of solvents 15 (Table 2); the particular examples cover a broad spectrum of solvent polarity, depending on the functionality of the covalently-attached moiety. For instance, the introduction of methyl methacrylate (MMA) oligomers lead to significantly increased dispersibility in butylacteate but reduced dispersion 20 in more polar ethanol. On the other hand, grafting of the CNTs with 2-(dimethylamino) ethyl methacrylate (DMAEMA) resulted in poor dispersion in butyl acetate but markedly improved dispersibility in acidic aqueous solution due the electrostatic stabilization of CNTs by protonated 25 amine groups. This change in dispersibilty is consistent with the altered thermodynamic surface properties of the grafted CNT, as measured by IGC. The dispersive surface energy of the grafted CNTs (Table 2) roughly correlates with the grafting ratio (Table 1); with increasing coverage of the 30 highly energetic graphitic surface, $\gamma^{\mathrm{d}}$ decreases. Changes in the $\mathrm{K}_{\mathrm{D}} / \mathrm{K}_{\mathrm{A}}$ ratios after grafting (Table 2) indicates altered surface characters due to the introduction of new functional surface groups. For instance, relative to the parent material, the $\mathrm{K}_{\mathrm{D}} / \mathrm{K}_{\mathrm{A}}$ ratio decreased for CNTs modified with acrylic 35 acid (AA), indicating a more electron accepting character, but increased for the DMAEMA-grafted CNTs, implying a more electron donating surface. These findings demonstrate that our methodology is an efficient and flexible route to tailor the CNT surface chemistry, rendering our approach a useful tool 40 to adapt as-produced CNTs to potential applications, such as sensors networks, filters, electrochemical device electrodes, or catalysis support materials. CNT functionalisation is required to improve the interfacial compatibility of the nanotubes with other components (such as electrolytes, reaction solvents, or 45 composite matrices) ${ }^{10,42,43}$ or to provide a direct function (for example, analyte binding, catalytic activity, photocharge generation). ${ }^{44-46}$ For instance, the gold-tagged CNTs, presented in Figure 6 could be useful materials in their own right as (electro)catalyst.

50 Our proposed thermochemical modification treatment offers several advantages over conventional CNT grafting strategies. Firstly, our approach exploits existing defect sites, minimising the framework damage and associated degradation of CNT properties. Existing defect chemistry, in contrast, 55 tends to use a strong preliminary acid oxidation that is known to cut and etch nanotubes. ${ }^{13}$ Many other conventional grafting and functionalisation reactions attack intact CNT sidewalls and, thereby, significantly increase the defect concentration directly. ${ }^{47}$ Secondly, the grafting reaction was found to be 60 highly effcient, with typical yields of grafted CNT product of around $90 \%$. The observed $10 \%$ loss of CNT material is due to handling errors which are expected to significantly decrease with scale up. Although only a small fraction of the monomer reservoir is reacted per cycle, the overall monomer 65 utilisation is high. The grafting efficiency of our methodology in the liquid setup was determined to be at least $99 \%$ for the MMA-grafted commercial CNTs, i.e. less than $1 \%$ of the original monomer was lost due to formation of homopolymer, enabling the re-use of monomer for future grafting cycles. The 70 high grafting efficiency can be attributed to initiation and propagation of the grafting reaction through surface-bound radical intermediates. In principle, the treatment can be carried out without creating any chemical waste; depending on the application, excess monomer may either remain in the 75 final product or be removed through evaporation under vacuum, making time-consuming filtration and washing procedures redundant. Thirdly, and perhaps most importantly, our methodology can be carried out as pure gas-phase reaction when comparatively volatile monomers, such as MMA and 80 acrylonitrile (AN), are used under vacuum conditions. The 
grafting ratios, as determined by TGA, and surface properties, as determined by gas chromatography, are comparable to the corresponding products obtained using the liquid-phase setup (Table 2). This particular approach has the additional 5 advantage that the inhibitor does not have to be removed from the monomer reservoir. Consequently, un-reacted monomer remains stabilized against self-polymerization. The gas-phase set-up is also easily scalable and compatible with existing CNT synthesis processes, rendering our methodology more 10 economically viable than existing grafting approaches.

\section{Conclusions}

The thermochemical approach introduced in this paper is a generic method to modify CNTs whilst minimizing damage to 15 the graphitic framework. The key step of the treatment is the activation of CNTs at high temperatures under inert atmosphere or in vacuum which results in the desorption of oxygen-containing functional groups at pre-existing defect sites and the generation of surface radicals. The reactive sites 20 can be utilized to initiate radical polymerization of functional monomers leading to the grafting of oligomers. The grafting ratios and average oligomer chain lengths of the modified CNTs lie between 1-8 wt\% and 1-70 monomeric units, respectively; the results depend on the reactivity and 25 flexibility of the organic reactant selected. Both dispersion studies and IGC characterisation indicate significantly altered CNT surface properties depending on the grafting ratio and functionality of the monomer. Our functionalisation approach combines versatility with the technological advantages of 30 solvent-free reactions and scalability. The treatment is of high efficiency due to the "grafting-from" reaction mechanism. The functionalisation can also be carried out as pure gas-phase reaction rendering it potentially compatible with existing gasphase processes for the commercial production of CNTs. 35 Significantly, the same approach should also apply to other technological important carbons, including blacks and fibers.

\section{Acknowledgements}

This work was supported by the Engineering and Physical Sciences Research Council (EPSRC) and Defence Science and 40 Technology Laboratory (DSTL). We would also like to thank Richard Winchester for taking TEM images.

\section{Notes and references}

${ }^{a}$ Dept. of Chemistry, Imperial College, London, SW7 2AZ, UK. Fax: +44(0)2075945801; Tel: +44(0)2075945825; E-mail: 45 m.shaffer@imperial.ac.uk

${ }^{b}$ Dept. of Chemical Engineering, Imperial College, London, SW7 2AZ, UK.

${ }^{c}$ Institute of Structural and Molecular Biology and London Centre for Nanotechnology, University College London, Gower Street, London, ${ }_{50}$ WCIE 6BT, UK.

$\dagger$ Electronic Supplementary Information (ESI) available: ESI includes additional information on how the grafting ratio, $\Delta$, was determined, the 55 derivatives of the TGA profiles presented in Figure 5, EPR spectra of heat-treated and air-exposed CNTs at room temperature, and additional characterization data for the grafted CNTs presented in Tables 2 and 3 (numerical values for the $\mathrm{K}_{\mathrm{A}}$ and $\mathrm{K}_{\mathrm{D}}$ numbers, for the $\mathrm{I}_{\mathrm{G}} / \mathrm{I}_{\mathrm{D}}$ ratios and for the concentrations of dispersed CNTs in various, additional solvents). See 60 DOI: 10.1039/b000000x/

\$ Footnotes should appear here. These might include comments relevant to but not central to the matter under discussion, limited experimental and spectral data, and crystallographic data.

65

1 M. C. Ma, T. C. Brown, and B. S. Haynes, Surface Science, 1993,297, 312.

2 A. Frumkin, Kolloid-Zeitschrift, 1930, 51, 123.

$70^{3}$ Y. A. Zarifyanz, V. F. Kiselev, N. N. Lezhnev, and O. V. Nikitina, Carbon, 1967, 5, 135.

$4 \quad$ P. M. Ajayan, Chemical Reviews, 1999, 99, 1787.

5 B. Njuguna, Advanced Engineering Materials, 2003, 5, 769.

6 J. N. Coleman, U. Khan, and Y. K. Gunko, Advanced Materials, $75 \quad 2006, \mathbf{1 8}, 689$.

7 Y. J. Lu, J. Li, J. Han, H. T. Ng, C. Binder, C. Partridge, and M. Meyyappan, Chemical Physics Letters, 2004, 391, 344.

8 B. Yoon and C. M. Wai, Journal of the American Chemical Society, 2005, 127, 17174.

${ }_{80}^{9}$ E. Katz, ChemPhysChem, 2004, 5, 1084.

10 C. A. Dyke and J. M. Tour, Journal of Physical Chemistry A, 2004, 108, 11151.

11 D. Tasis, N. Tagmatarchis, A. Bianco, and M. Prato, Chemical Reviews, 2006, 106, 1105.

85 C. N. R. Rao and A. Govindaraj, 'Nanotubes and Nanowires', ed. P. O'Brian, H. Kroto, and H. Craighead, Royal Society of Chemistry, 2005.

13 A. Hirsch, Angewandte Chemie International Edition, 2002, 41, 1853.

${ }_{90}{ }^{14}$ M. Hamon, H. Hui, P. Bhowmik, M. E. Itkis, and R. C. Haddon, Applied Physics A, 2002, 74, 333.

15 M. Holzinger, O. Vostrowsky, A. Hirsch, F. Hennrich, M. Kappes, R. Weiss, and F. Jellen, Angewandte Chemie International Edition, 2001, 40, 4002 .

${ }_{95}{ }^{16}$ Y. S. Chen, R. C. Haddon, S. Fang, A. M. Rao, P. C. Eklund, W. H. Lee, E. C. Dickey, E. A. Grulke, and R. E. Smalley, Journal of Materials Research, 1998, 13, 2423.

17 J. Bahr, J. Yang, D. V. Kosynkin, M. J. Bronikowski, R. E. Smalley, and J. M. Tour, Journal of the American Chemical Society, 2001, $100 \quad \mathbf{1 2 3}, 6536$.

18 S. Campidelli, C. Sooambar, E. Lozano Diz, C. Ehli, D. M. Guldi, and M. Prato, Journal of the American Chemical Society, 2006, 128, 12544.

19 C. M. Homenick, G. Lawson, and A. Adronov, Polymer Reviews, 2007, 47, 265.

20 X. D. Lou, C. Detrembleur, V. Sciannamea, C. Pagnoulle, and R. Jerome, Polymer, 2004, 45, 6097.

21 Y. Q. Liu, Z. L. Yao, and A. Adronov, Macromolecules, 2005, 38, 1172 .

$110^{22}$ C. E. Hamilton, J. R. Lomeda, Z. Z. Sun, J. M. Tour, and A. R. Barron, Nano Research, 2010, 3, 138.

23 Z. L. Yao, N. Braidy, G. A. Botton, and A. Adronov, Journal of the American Chemical Society, 2003, 125, 16015.

24 M. Dehonor, K. Masenelli-Varlot, A. Gonzalez-Montiel, C. Gauthier,

115 J. Y. Cavaille, and M. Terrones, Journal of Nanoscience and Nanotechnology, 2007, 7, 3450.

25 J. Cui, W. P. Wang, Y. Z. You, C. H. Liu, and P. H. Wang, Polymer, $2004, \mathbf{4 5}, 8717$.

26 T. Nakajima, S. Kasamatsu, and Y. Matsuo, European Journal of

$120 \quad$ Solid State and Inorganic Chemistry, 1996, 33, 831.

27 M. Q. Tran, C. Tridech, A. Alfrey, A. Bismarck, and M. S. P. Shaffer, Carbon, 2007, 45, 2341.

28 Z. Y. Hou, B. C. Cai, H. Liu, and D. Xu, Carbon, 2008, 46, 405.

29 A. Bismarck, C. Wuertz, and J. Springer, Carbon, 1999, 37, 1019.

12530 R. Andrews, D. Jacques, A. M. Rao, F. Derbyshire, D. Qian, X. Fan, E. C. Dickey, and J. Chen, Chemical Physics Letters, 1999, 303, 467. 
31 R. Menzel, A. Lee, A. Bismarck, and M. S. P. Shaffer, Langmuir, 2009, 25, 8340.

32 M. Voll and H. P. Boehm, Carbon, 1970, 8, 741.

33 J. Carlsson, F. Hanke, S. Linic, and M. Scheffler, Physical Review Letters, 2009, 102, 166104.

34 S. Hamdi, B. Hamdi, Z. Kessaissia, H. Barthel, H. Balard, and J. B. Donnet, Journal of Chromatography A, 2002, 969, 143.

35 M. Kosaka, T. W. Ebbesen, H. Hiura, and K. Tanigaki, Chemical Physics Letters, 1994, 225, 161.

$10^{36}$ F. Beuneu, C. l'Huillier, J. P. Salvetat, J. M. Bonard, and L. Forro, Physical Review B, 1999, 59, 5945.

37 C. Goze-Bac, S. Latil, P. Lauginie, V. Jourdain, J. Conard, L. Duclaux, A. Rubio, and P. Bernier, Carbon, 2002, 40, 1825.

38 B. Corzilius, K. P. Dinse, K. Hata, M. Haluska, V. Skakalova, and S.

15 Roth, Physica Status Solidi B-Basic Solid State Physics, 2008, 245, 2251.

39 K. Sendt and B. S. Haynes, The Journal of Physical Chemistry C, 2007, 111, 5465.

40 T. J. Frankcombe and S. C. Smith, Carbon, 2004, 42, 2921.

$20{ }^{41}$ K. S. Coleman, S. R. Bailey, S. Fogden, and M. L. H. Green, Journal of the American Chemical Society, 2003, 125, 8722.

42 W. Zhang, J. K. Sprafke, M. L. Ma, E. Y. Tsui, S. A. Sydlik, G. C. Rutledge, and T. M. Swager, Journal of the American Chemical Society, 2009, 131, 8446.

$25{ }^{43}$ L. Q. Liu, A. H. Barber, S. Nuriel, and H. D. Wagner, Advanced Functional Materials, 2005, 15, 975.

44 R. M. Lucente-Schultz, V. C. Moore, A. D. Leonard, B. K. Price, D. V. Kosynkin, M. Lu, R. Partha, J. L. Conyers, and J. M. Tour, Journal of the American Chemical Society, 2009, 131, 3934.

${ }_{30}{ }^{45}$ P. Singh, J. Kumar, F. M. Toma, J. Raya, M. Prato, B. Fabre, S. Verma, and A. Bianco, Journal of the American Chemical Society, 2009, 131, 13555.

46 S. M. Kaniber, M. Brandstetter, F. C. Simmel, I. Carmeli, and A. W. Holleitner, Journal of the American Chemical Society, 2010, 132, $35 \quad 2872$.

47 X. M. Sui, S. Giordani, M. Prato, and H. D. Wagner, Applied Physics Letters, 2009, 95. 